\title{
A phase I clinical study of immunotherapy for advanced colorectal cancers using carcinoembryonic antigen-pulsed dendritic cells mixed with tetanus toxoid and subsequent IL-2 treatment
}

\author{
Ko-Jiunn Liu ${ }^{1,2,3^{*}}$ (D), Tsu-Yi Chao ${ }^{4,6}$, Jang-Yang Chang ${ }^{1,7}$, Ann-Lii Cheng ${ }^{5}$, Hui-Ju Ch'ang ${ }^{1}$, Woei-Yau Kao ${ }^{4,8}$,
} Yu-Chen Wu', Wei-Lan Yu', Tsai-Rong Chung ${ }^{1}$ and Jacqueline Whang-Peng 1,5, ${ }^{*}$

\begin{abstract}
Background: To better evaluate and improve the efficacy of dendritic cell (DC)-based cancer immunotherapy, we conducted a clinical study of patients with advanced colorectal cancer using carcinoembryonic antigen (CEA)-pulsed DCs mixed with tetanus toxoid and subsequent interleukin-2 treatment. The tetanus toxoid in the vaccine preparation serves as an adjuvant and provides a non-tumor specific immune response to enhance vaccine efficacy. The aims of this study were to (1) evaluate the toxicity of this treatment, (2) observe the clinical responses of vaccinated patients, and (3) investigate the immune responses of patients against CEA before and after treatment.

Methods: Twelve patients were recruited and treated in this phase I clinical study. These patients all had metastatic colorectal cancer and failed standard chemotherapy. We first subcutaneously immunized patients with metastatic colorectal cancer with $1 \times 10^{6}$ CEA-pulsed DCs mixed with tetanus toxoid as an adjuvant. Patients received 3 successive injections with $1 \times 10^{6}$ CEA-pulsed DCs alone. Low-dose interleukin-2 was administered subcutaneously following the final DC vaccination to boost the growth of $T$ cells. Patients were evaluated for adverse event and clinical status. Blood samples collected before, during, and after treatment were analyzed for $T$ cell proliferation responses against CEA.

Results: No severe treatment-related side effects or toxicity was observed in patients who received the regular $4 \mathrm{DC}$ vaccine injections. Two patients had stable disease and 10 patients showed disease progression. A statistically significant increase in proliferation against CEA by T cells collected after vaccination was observed in 2 of 9 patients.

Conclusions: The results of this study indicate that it is feasible and safe to treat colorectal cancer patients using this protocol. An increase in the anti-CEA immune response and a clinical benefit was observed in a small fraction of patients. This treatment protocol should be further evaluated in additional colorectal cancer patients with modifications to enhance T cell responses.
\end{abstract}

Trial registration: ClinicalTrials.gov (identifier NCT00154713), September 8, 2005

Keywords: Colorectal cancer, Carcinoembryonic antigen, Dendritic cell, Tetanus toxoid, Interleukin-2

(Continued on next page)

\footnotetext{
* Correspondence: kojiunn@nhri.org.tw; jawpeng@nhri.org.tw

${ }^{1}$ National Institute of Cancer Research, National Health Research Institutes,

Tainan, Taiwan

Full list of author information is available at the end of the article
} 


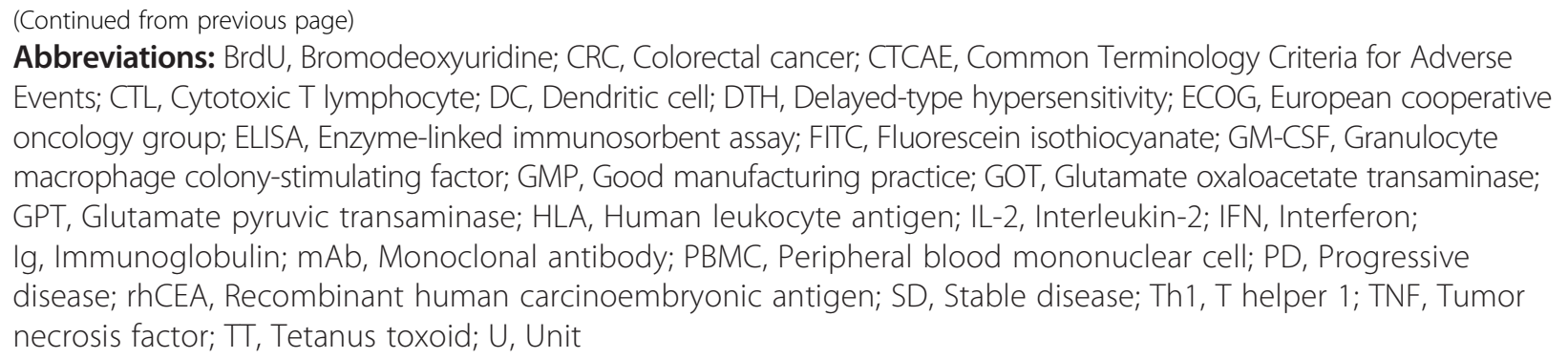

\section{Background}

Colorectal cancer $(\mathrm{CRC})$ is one of the most common and deadly cancers in Taiwan and the United States [1]. Although recent developments in surgical management, chemotherapy, and biological therapy have improved the survival of early-stage CRC patients, the treatment of patients with late-stage CRC remains difficult [2]. The use of an anti-immune checkpoint antibody has revolutionized the clinical treatment of many cancers [3]. Indications for melanoma and non-small cell lung carcinoma have been approved, and the application of anticheckpoint antibodies in other cancer types, including CRC, has been actively evaluated in the clinical setting [4-6]. However, the results of several clinical studies revealed that anti-immune checkpoint antibodies for many cancers may not function as effectively as in melanoma and lung cancers [7].

For CRC, a better therapeutic result was observed in patients with mismatch-repair deficiency than in those without this deficiency [8]. Recent reports suggested a positive relationship between clinical responses and the amounts of tumor mutation or neoantigen in patients receiving anti-immune checkpoint antibody therapy [9]. It has been hypothesized that CRC patients with mismatchrepair deficiency may accumulate a larger number of mutations and generate abundant neoantigens in their tumors, thus favoring an approach involving the reactivation of pre-existing $\mathrm{T}$ cells using the anti-immune checkpoint antibody. However, patients with mismatch-repair deficiency represent a very small fraction of CRC patients $[10,11]$. Therefore, efforts to combine the anti-immune checkpoint antibody with other types of treatment have been proposed to increase the therapeutic efficacy for cancers displaying a lower response rate when treated with anti-immune checkpoint antibody alone [12]. One of the these approaches involves vaccinating CRC and other cancer patients with tumor-associated antigens to increase the number or diversity of $\mathrm{T}$ cells and followed by providing an anti-immune checkpoint antibody to strengthen or prolong $\mathrm{T}$ cell responses $[6,13,14]$. The dendritic cell (DC)-based cancer vaccine appears to be the most promising method for boosting the patient immune responses against tumors. DCs are the most important antigenpresenting cells in the body, and DC-based cancer immunotherapy has been extensively explored in recent years $[15,16]$. Provenge (sipuleucel-T), a product based on antigen-pulsed antigen-presenting cells for the treatment of hormone-refractory prostate cancer, was approved by the FDA in 2010 [17], demonstrating the therapeutic potential of such application.

To develop an alternative therapy for patients who have failed standard chemotherapy and provide an effective adjuvant therapy for cancer patients, DC-based immunotherapy for CRC patients has been examined [18]. Elevated expression of carcinoembryonic antigen (CEA) was observed in most CRC both in the serum and tumor [19]. Although CEA is also expressed in normal colon epithelial cells, the expression level is low. Previous immunotherapies targeting CEA have shown that immune responses against CEA were elevated in patients without severe autoimmune responses [20, 21], suggesting that CEA may be useful as a tumor-associated antigen. In our previous pilot study, we pulsed patient's autologous DCs with synthetic peptides representing the CTL epitopes on CEA. All patients tolerated the intranodal injections of DC vaccines well and no severe toxicity or autoimmunity was observed. An increase in the number of CEA-specific T cells after DC vaccination was detected in 6 of the 9 patients evaluated [20]. Two of 10 patients had stable diseases. The results of this pilot trial suggested that the vaccination procedure is feasible and safe, and that this treatment may generate or boost tumor-antigen-specific $\mathrm{T}$ cell responses in many patients.

Studies by others and us indicated that tumor-associated antigen-specific $\mathrm{T}$ cells responses can be generated in most cancer patients after DC vaccination, but these $\mathrm{T}$ cell responses are generally short-lived [20, 22, 23]. This may significantly limit treatment efficacy. In our previous pilot study [20], we chose to use synthetic peptides representing the CTL epitopes on CEA as the source of antigen to pulse DCs. This approach has the benefit of generating CEA peptide-specific $\mathrm{CD}^{+} \mathrm{T}$ cell responses but has the limitation that we can only vaccinate a portion of cancer patients that express a particular HLA phenotype and that 
CEA-specific $\mathrm{CD} 4^{+} \mathrm{T}$ cell responses may not be activated. Therefore, we conducted this phase I clinical study to evaluate and improve the efficacy of DC-based immunotherapy using CEA-pulsed DCs mixed with tetanus toxoid (TT) and subsequent interleukin (IL)-2 treatment. The use of whole CEA protein as the source of antigen will provide potential epitopes recognized by $\mathrm{CD}^{+}$and $\mathrm{CD}^{+} \mathrm{T}$ cells derived from patients with different HLA phenotypes. TT is a very strong recall antigen and induces a delayed-type hypersensitivity (DTH) response. We hypothesize that the local DTH response induced by TT further activates co-injected DCs and promotes their $\mathrm{T}$ cell-stimulating functions. Low-dose IL-2 was administered subcutaneously following DC vaccination in this study to further boost and maintain $\mathrm{T}$ cell growth. The results of this clinical study, including the safety evaluation, clinical status, and immune responses of patients, are reported.

\section{Methods}

\section{Patient characteristics}

Twelve patients, 6 from the National Taiwan University Hospital and 6 from the Tri-Service General Hospital, were enrolled in this study between 2006 and 2010. This clinical protocol was approved by the Research Ethics Committee of the National Taiwan University Hospital (protocol number 27MD02) and the Institutional Review Board of the Tri-Service General Hospital/National Defense Medical Center (protocol number 095-04-003), and further approved by the Department of Health (currently the Ministry of Health and Welfare), Taiwan. Signed informed consent was obtained from each patient before the recruitment. All patients had experienced metastasis from their primary colorectal cancer and had failed the first-line chemotherapy regimen containing CPT-11 (irinotecan) or oxaliplatin. Patients were more than 20 years old and their serum CEA levels were at least 5-fold higher than the normal limit. All patients had adequate bone marrow, liver, and renal function defined as white blood cell $\geq 3500 / \mathrm{mm}^{3}$, neutrophil $\geq 1500 / \mathrm{mm}^{3}$, lymphocyte $\geq 1000 / \mathrm{mm}^{3}$, platelet $\geq 100,000 / \mathrm{mm}^{3}$, glutamate oxaloacetate transaminase (GOT), and glutamate pyruvic transaminase $(\mathrm{GPT}) \leq 5$-fold of the normal range, bilirubin $\leq 1.5$-fold of the normal range, and creatinine $\leq 2$-fold of the normal range. Patients had appropriate immune function, defined as IgG $\geq 614 \mathrm{mg} / \mathrm{dL}$, IgM $\geq 53 \mathrm{mg} / \mathrm{dL}$ and the DTH test showed positive results $(\geq 5 \mathrm{~mm}$ in diameter). Patient performance status (PS) ranged from 0 to 2 on the ECGO scale. Patients with central nervous system metastasis, autoimmune disease, or active/chronic infection and patients who received chemotherapy, steroid, or biological treatment within 4 weeks before enrollment were excluded from this study. The complete inclusion and exclusion criteria of patient selection were listed in the Additional file 1. Selected patient characteristics are shown in Table 1.

\section{Preparation of human DCs from peripheral blood mononuclear cells (PBMCs)}

PBMCs derived from apheresis were further enriched by density gradient centrifugation in lymphocyte separation medium (Lonza, Basel, Switzerland). The PBMCs were incubated for $2 \mathrm{~h}$ at $37{ }^{\circ} \mathrm{C}$ in $\mathrm{X}$-VIVO15 medium (Lonza) in a plastic flask, and adherent cells were cultured in X-VIVO15 medium containing $2 \%$ heatinactivated autologous plasma, $1000 \mathrm{U} / \mathrm{mL}$ human interleukin-4 (IL-4, GMP-grade, Strathmann Biotec AG, Hannover, Germany), and $500 \mathrm{U} / \mathrm{mL}$ granulocyte macrophage colony-stimulating factor (GM-CSF, GMP-grade, GENTAUR Belgium BVBA, Kampenhout, Belgium). On day 6, loosely attached or floating immature DCs were collected. The immature DCs were stored in the gas phase of a liquid nitrogen tank until use. No bacteria, fungus, mycoplasma, or endotoxin contamination were detected in any cell culture products. The Gram's iodine stain method was used for bacteria contamination evaluation. The detection of bacteria and fungus contamination was further performed by a growthbased rapid microbiological method with the BacT/ ALERT automatic culture system (bioMerieux SA, Marcy I'Etoile, France). The detection of mycoplasma contamination was performed using a PCR-based method (e-Myco plus mycoplasma PCR detection kit, iNtRON Biotechnology, Kyungki-Do, Korea). The endotoxin contamination was determined using a Limius Amebocyte Lysate QCL-1000 Endotoxin test (Lonza).

\section{Vaccine preparation and vaccination protocol}

Thawed immature DCs $\left(3 \times 10^{6}\right)$ were suspended in $1 \mathrm{~mL}$ of X-VIVO15 medium and cultured with $25 \mu \mathrm{g} / \mathrm{mL}$ of

Table 1 Characteristics of enrolled cancer patients

\begin{tabular}{lllll}
\hline Patient & Sex & Age & PS & Metastasis site \\
\hline 1 & Male & 68 & 1 & Liver, lung, and bone \\
2 & Female & 49 & 1 & Liver \\
3 & Female & 48 & 1 & Liver \\
4 & Female & 62 & 2 & Liver and lung \\
5 & Male & 45 & 1 & Rectum \\
6 & Male & 58 & 1 & Liver, lung, bone and adrenal glands \\
7 & Male & 52 & 0 & Liver \\
8 & Male & 48 & 1 & Liver \\
9 & Female & 52 & 1 & Liver, lung and bone \\
10 & Male & 80 & 1 & Liver, lung, and lymph node \\
11 & Male & 65 & 1 & Abdominal wall \\
12 & Male & 62 & 0 & Liver \\
\hline
\end{tabular}


recombinant human CEA (rhCEA, Protein Sciences Corp., Meriden, CT, USA) at $37{ }^{\circ} \mathrm{C}$. After 3 h, rhCEApulsed DCs were collected and matured by culturing the cells in X-VIVO15 medium containing $2 \%$ heatinactivated autologous plasma and $1000 \mathrm{U} / \mathrm{mL}$ tumor necrosis factor- $\alpha$ (TNF- $\alpha$, CELL-GRO, CellGenix, Freiburg im Breisgau, Germany), recombinant human interferongamma (IFN- $\gamma$, GMP-grade, GENTAUR Belgium BVBA), and human IL-4 (GMP-grade, Strathmann) in a T25 flask at $37{ }^{\circ} \mathrm{C}$ for $18 \mathrm{~h}$. The cells were collected and used as rhCEA-pulsed, matured DCs. The procedure of pulsing DCs with rhCEA was modified from a previous study [24]. In this study, we did not actually verify the efficiency of CEA presentation by DCs pulsed with rhCEA. Collected DCs were washed five times with normal saline, and $1.5 \times 10^{6}$ DCs were suspended in $0.3 \mathrm{~mL}$ normal saline supplemented with $1 \%$ heat-inactivated autologous plasma. To remove cell clusters, the cell suspension was slowly passed through a 25 -gauge needle. The cell suspension was then injected subcutaneously near one inguinal lymph node of the patient. For the first $\mathrm{DC}$ vaccine injection, the cell suspension was mixed with diluted tetanus toxoid $(0.04 \mathrm{U}$ in $0.1 \mathrm{~mL}$, Adimmune Corp., Taichung, Taiwan) before injection. Patients were vaccinated once per week for 3 weeks followed by a boost injection 2 weeks later. IL-2 (Proleukin, Chiron, Emeryville, CA, USA) was injected subcutaneously $\left(5 \times 10^{6} \mathrm{IU} / \mathrm{m}^{2}\right.$, twice/day $\times 3$ days $) 1$ week after the fourth DC vaccination. Whole blood $(30 \mathrm{~mL})$ was collected from the patients 2 weeks after the first and last injections. PBMCs were purified and cryopreserved to evaluate the immune responses against CEA. Patients received the first $C T$ examination 6 weeks after the first DC vaccination and every 2 months afterward. Patients showing stable or better clinical responses received 1 boost injection of DC vaccine every 2 months until disease progression. The schedule of DC vaccination and treatment of this study is shown in Fig. 1.

\section{Flow cytometry analysis of immature DCs}

Immature DCs were stained with different fluorescencelabeled monoclonal antibodies (mAbs) and then analyzed using a flow cytometer (FACSCalibur; BD Biosciences, Franklin Lakes, NJ, USA). The mAbs used in the study included: FITC-anti-HLA-DR (Beckman Coulter, Brea, CA, USA), phycoerythrin-anti-CD86 (Beckman Coulter), FITC-anti-CD80 (Immunotech, Marseille Cedex, France), phycoerythrin-anti-CD86 (Beckman Coulter), phycoerythrin-anti-CD83 (Immunotech, Marseille Cedex, France), phycoerythrin-anti-CD14 (BD Biosciences), and FITC-anti-CD40 (Biolegend, San Diego, CA, USA). Isotype-matched control mAbs were obtained from Biolegend. Results were expressed as the percentage of cells stained positive for a given mAb.

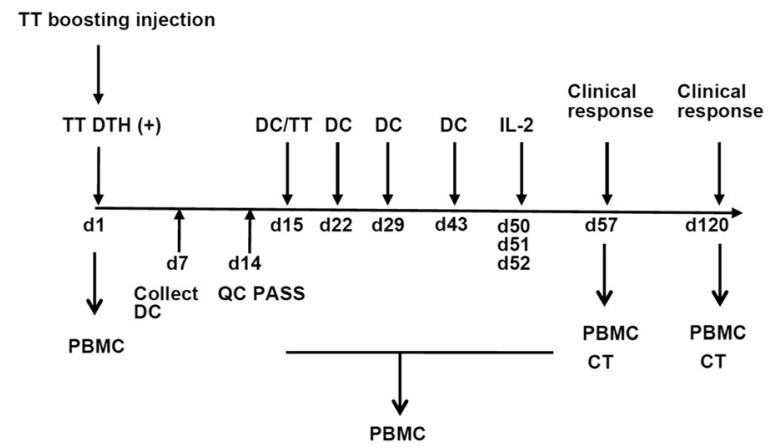

Fig. 1 Summary of treatment procedures in this study. Enrolled patients were injected with tetanus toxoid (TT), and those with positive TT DTH responses were subjected to leukopheresis to generate DCs for vaccine preparation. Cells were cultured in GM-CSF and IL-4 to generate immature DCs (day 1, d1). After 6 days, immature DCs were collected and checked for compliance with QC requirements (d7). DC preparations passed for QC were thawed on d14 and pulsed with rhCEA for $3 \mathrm{~h}$ and then stimulated with TNF- $\alpha$ and INF- $\gamma$ for $16 \mathrm{~h}$ to generated mature DCs. Next, $1 \times 10^{6}$ rhCEA-pulsed DCs were injected subcutaneously into patients on days 15, 22, 29, and 43. For the first injection, the DC vaccine was mixed with $\Pi$. One week after the last DC vaccine injection (d50), patients were subcutaneously injected with IL-2 for 3 days (d51-d53). PBMCs were collected before, during, and after DC vaccination for immune responses analysis. Patients were subjected to CT examination for clinical responses 6 weeks after the first DC vaccine injection (d57), and every 2 months afterwards until disease progression

\section{T-cell proliferation assay}

PBMCs collected before and after vaccination were thawed at the same time for immunologic analysis. Three replicates of $1 \times 10^{5}$ PBMCs were cultured in 96-well culture plates for 5 days in RPMI-1640 supplemented with $5 \%$ human type- $\mathrm{AB}$ serum (Lonza) in the presence of 0 (PBS), 5 , 10, 25, or $50 \mu \mathrm{g} / \mathrm{mL}$ rhCEA protein (Fitzgerald, Fitzgerald Industries International. Acton, MA, USA). Cellular proliferation was determined using a bromodeoxyuridine (BrdU) incorporation enzyme-linked immunosorbent assay (ELISA) kit (Roche Diagnostics GmbH, Mannheim, Germany). T cell proliferation status was expressed as the OD value measured at $450 \mathrm{~nm}$ (reference wavelength $650 \mathrm{~nm}$ ). The raw data of $\mathrm{T}$ cell proliferation assay was provided in the Additional file 2.

\section{Toxicity and clinical evaluation}

Toxicity grading was conducted and recorded according to National Cancer Institute Common Terminology Criteria for Adverse Events (CTCAE) v4.0. Clinical tumor responses were defined following the Response Evaluation Criteria in Solid Tumors v1.0.

\section{Statistical analysis}

Data are presented as mean \pm SD and differences between means were analyzed with the Student's $T$ test using 
Microsoft Excel software (Redmond, WA, USA). Differences were considered significant at $P<0.05$.

\section{Results}

Patients and vaccine preparation

Twelve patients were enrolled and treated in this clinical study (Table 1). All patients recruited showed proper bone marrow, liver, kidney, and immune functions and fit the inclusion and exclusion criteria of this study. Selected baseline clinical data of these patients are listed in Tables 2 and 3. These patients all displayed positive DTH responses against tetanus toxoid after the boosting injection and had adequate serum IgG and IgM levels (Table 3), suggesting proper basic immune functions after previous chemotherapy. The schedule of DC vaccination in this study is shown in Fig. 1. The DCs generated from patients' mononuclear cells displayed proper surface markers (more than $80 \%$ positive for HLA-DR, CD86, and CD40) and met the release criteria of the inprocess cell products (Table 4). For each DC vaccine preparation, the supernatant from the day 6 DC culture and supernatant after the last washing were examined for contamination with endotoxin, mycoplasma, fungus, and bacteria. All samples analyzed were negative for microorganism contamination and the endotoxin level was always below 0.15 endotoxin $\mathrm{U} / \mathrm{mL}$. These results indicate that the quality of our vaccine product is adequate.

\section{Adverse events and autoimmune profiles}

The primary endpoint of this study was the safety of the treatment procedure. No severe treatment-related side effects or toxicity was observed in patients who received the regular $4 \mathrm{DC}$ vaccine injections. However, patients 2 and 8 showed early disease progression during the treatment period and only received 2 and 3 DC vaccinations, respectively. Some evaluation data were not available

Table 2 Baseline clinical data (1)

\begin{tabular}{llllll}
\hline Patient & CEA & Leukocyte & Neutrophil & Lymphocyte & Platelets \\
\hline 1 & 82.3 & 4460 & 3010 & 1057 & 310,000 \\
2 & 323.3 & 7310 & 5695 & 1301 & 240,000 \\
3 & 53.5 & 5280 & 3559 & 1362 & 217,000 \\
4 & 645.7 & 7130 & 4442 & 2081 & 207,000 \\
5 & 391.2 & 6100 & 4111 & 1482 & 250,000 \\
6 & 291.7 & 7700 & 5328 & 1371 & 279,000 \\
7 & 1388.1 & 13700 & 9410 & 1980 & 253,000 \\
8 & 849 & 7300 & 4679 & 1365 & 229,000 \\
9 & 500.6 & 8730 & 6590 & 1090 & 275,000 \\
10 & 60.3 & 5970 & 3647 & 1528 & 146,000 \\
11 & 298.8 & 9740 & 7305 & 1705 & 350,000 \\
12 & 28.7 & 5330 & 2740 & 2180 & 205,000 \\
\hline
\end{tabular}

Table 3 Baseline clinical data (2)

\begin{tabular}{|c|c|c|c|c|c|}
\hline Patient & GOT/GPT & Bilirubin & Creatinine & $\begin{array}{l}\lg G \\
\lg M\end{array}$ & DTH skin test \\
\hline 1 & $26 / 40$ & 0.89 & 1 & $\begin{array}{l}\operatorname{lgG}(1170) \\
\operatorname{lgM}(58.4)\end{array}$ & $16 \mathrm{~mm} \times 15 \mathrm{~mm}$ \\
\hline 2 & $47 / 38$ & 1.15 & 0.8 & $\begin{array}{l}\operatorname{lgG}(1330) \\
\operatorname{lgM}(79.8)\end{array}$ & $10 \mathrm{~mm} \times 7 \mathrm{~mm}$ \\
\hline 3 & $19 / 14$ & 1.0 & 0.8 & $\begin{array}{l}\lg G(1530) \\
\operatorname{lgM}(54.9)\end{array}$ & $5 \mathrm{~mm} \times 5 \mathrm{~mm}$ \\
\hline 4 & $38 / 19$ & 0.95 & 0.7 & $\begin{array}{l}\lg G(1890) \\
\lg M(56.2)\end{array}$ & $30 \mathrm{~mm} \times 30 \mathrm{~mm}$ \\
\hline 5 & $20 / 23$ & 0.7 & 1.1 & $\begin{array}{l}\operatorname{lgG}(1320) \\
\lg M(96)\end{array}$ & $6 \mathrm{~mm} \times 6 \mathrm{~mm}$ \\
\hline 6 & $22 / 9$ & 0.9 & 1.2 & $\begin{array}{l}\lg G(1560) \\
\lg M(83)\end{array}$ & $8 \mathrm{~mm} \times 11 \mathrm{~mm}$ \\
\hline 7 & $43 / 34$ & 0.4 & 1.1 & $\begin{array}{l}\lg G(821) \\
\lg M(56)\end{array}$ & $8 \mathrm{~mm} \times 10 \mathrm{~mm}$ \\
\hline 8 & $50 / 41$ & 1.4 & 0.8 & $\begin{array}{l}\lg G(1500) \\
\operatorname{lgM}(64)\end{array}$ & $10 \mathrm{~mm} \times 8 \mathrm{~mm}$ \\
\hline 9 & $39 / 15$ & 0.4 & 0.5 & $\begin{array}{l}\lg G(1150) \\
\lg M(86)\end{array}$ & $12 \mathrm{~mm} \times 10 \mathrm{~mm}$ \\
\hline 10 & $40 / 24$ & 0.7 & 0.8 & $\begin{array}{l}\lg G(1630) \\
\operatorname{lgM}(76)\end{array}$ & $11 \mathrm{~mm} \times 11 \mathrm{~mm}$ \\
\hline 11 & $19 / 12$ & 0.53 & 0.9 & $\begin{array}{l}\lg G(1580) \\
\lg M(83.9)\end{array}$ & $7 \mathrm{~mm} \times 9 \mathrm{~mm}$ \\
\hline 12 & $25 / 24$ & 1.5 & 0.9 & $\begin{array}{l}\operatorname{lgG}(1270) \\
\lg M(93.2)\end{array}$ & $12 \mathrm{~mm} \times 12 \mathrm{~mm}$ \\
\hline
\end{tabular}

from these 2 patients because of their early withdrawal from the study. The remaining 10 patients received at least 4 standard DC vaccinations and subsequent IL-2 administration. A comparison of liver and kidney functions of the patients before, during, and after DC vaccination is shown in Table 5. Patients 4 and 8 showed a more

Table 4 Surface marker expression of DC 6 days after culture from PBMCs

\begin{tabular}{llll}
\hline $\begin{array}{l}\text { Marker } \\
\text { Patient }\end{array}$ & HLA-DR & CD40 \\
\hline 1 & $93.39^{\text {a }}$ & 96.47 & 98.22 \\
2 & 95.4 & 85.36 & 99.41 \\
3 & 83.14 & 94.17 & 95.51 \\
4 & 95.2 & 94.98 & 96.64 \\
5 & 97.92 & 93.64 & 98.96 \\
6 & 95.98 & 87.72 & 94.75 \\
7 & 84.4 & 93.08 & 97.24 \\
8 & 86.25 & 95.35 & 99.18 \\
9 & 94.03 & 96.22 & 94.54 \\
10 & 90.67 & 93.29 & 97.71 \\
11 & 89.52 & 97.43 & 98.25 \\
12 & 95.9 & 93.76 & 95.97 \\
Mean \pm SD & $91.8 \pm 4.96$ & $93.5 \pm 5.34$ & $97.2 \pm 1.71$ \\
${ }^{a}$ Results were expressed as the percentage of cells stained positive for a given mAb
\end{tabular}


Table 5 Comparison of liver and kidney function of patients before, during, and after DC vaccination

\begin{tabular}{|c|c|c|c|c|c|c|c|c|c|}
\hline \multirow[t]{3}{*}{ Patient } & \multicolumn{6}{|c|}{ Liver function } & \multicolumn{3}{|c|}{ Kidney function } \\
\hline & \multicolumn{3}{|l|}{ GOT/GPT } & \multicolumn{3}{|l|}{ Bilirubin } & \multicolumn{3}{|c|}{ Creatinine } \\
\hline & $\begin{array}{l}\text { Day } 0 \\
\text { (before) }\end{array}$ & $\begin{array}{l}\text { Day } 36 \\
\text { (during) }\end{array}$ & $\begin{array}{l}\text { Day } 57 \\
\text { (after) }\end{array}$ & $\begin{array}{l}\text { Day } 0 \\
\text { (before) }\end{array}$ & $\begin{array}{l}\text { Day } 36 \\
\text { (during) }\end{array}$ & $\begin{array}{l}\text { Day } 57 \\
\text { (after) }\end{array}$ & $\begin{array}{l}\text { Day } 0 \\
\text { (before) }\end{array}$ & $\begin{array}{l}\text { Day } 36 \\
\text { (during) }\end{array}$ & $\begin{array}{l}\text { Day } 57 \\
\text { (after) }\end{array}$ \\
\hline 1 & $26 / 40$ & $40 / 33$ & $47 / 37$ & 0.89 & 1.04 & 1.35 & 1.0 & 1.1 & 1.0 \\
\hline 2 & $47 / 38$ & off $^{a}$ & off & 1.15 & off & off & 0.8 & off & off \\
\hline 3 & $19 / 14$ & $27 / 26$ & $54 / 84$ & 1.0 & 0.68 & 0.65 & 0.8 & 0.7 & 0.7 \\
\hline 4 & $38 / 19$ & $94 / 37$ & off & 0.95 & 1.01 & off & 0.7 & 0.8 & off \\
\hline 5 & $20 / 23$ & $17 / 17$ & 20/39 & 0.7 & 1.1 & 0.5 & 1.1 & 1.2 & 1.0 \\
\hline 6 & $22 / 9$ & $26 / 11$ & $22 / 13$ & 0.9 & 0.8 & 1.0 & 1.2 & 2.2 & 2.3 \\
\hline 7 & $24 / 39$ & $52 / 55$ & $47 / 46$ & 0.4 & 1.2 & 1.0 & 1.0 & 0.9 & 0.8 \\
\hline 8 & $50 / 41$ & $132 / 61$ & off & 1.4 & 35.5 & off & 0.8 & 0.8 & off \\
\hline 9 & $39 / 15$ & $29 / 14$ & $41 / 28$ & 0.4 & 0.4 & 0.3 & 0.5 & 0.5 & 0.4 \\
\hline 10 & $32 / 17$ & $53 / 30$ & $49 / 48$ & 0.9 & 0.8 & 0.9 & 0.9 & 0.8 & 0.7 \\
\hline 11 & $19 / 12$ & 20/11 & $23 / 14$ & 0.53 & 0.3 & 0.33 & 0.9 & 0.8 & 0.8 \\
\hline 12 & $25 / 24$ & $41 / 45$ & $28 / 30$ & 1.5 & 2.25 & 1.53 & 0.9 & 1.0 & 1.0 \\
\hline
\end{tabular}

a" off" indicates samples not available for analysis because of withdrawal or termination of enrolled patients from this study

substantial increase in GOT during the study (day 36) and were subsequently removed from the study because of disease progression. Several other patients showed minor elevations in GOT/GPT, but the level remained within the initial patient selection criteria (5-fold of normal value). Patient 12 showed a minor increase in bilirubin on day 36, but returned to the initial level on day 57. Patient 8 showed a substantial increase in bilirubin on day 36 and was subsequently removed from the study because of disease progression. Patient 6 showed an increase in creatinine on days 36 and 57, but the level remained within the initial patient selection criteria (2-fold of normal value). These detection values were within the limit of grade II toxicity.

Autoimmune factors, including anti-nuclear antibody, rheumatoid factor, and thyroglobulin antibody, were not substantially increased after treatment in most patients. However, final data were unavailable from three patients because of disease progression (Table 6). Patient 9 showed a higher level of rheumatoid factor before treatment, and the level slightly decreased during and after the $4 \mathrm{DC}$ vaccine injections. Patient 12 showed a higher level of thyroglobulin antibody before treatment, and the level decreased during and after the $4 \mathrm{DC}$ vaccine injections. Overall, we observed no significant changes in the autoimmune profiles of the patients.

In the evaluation of other side effects and toxicity (Table 7), patient 1 had grade III diarrhea before treatment and the symptom persisted during the trial period. Patient 2 had grade III diarrhea on day 22, which was resolved soon after. Patient 6 had grade II creatinine elevation, likely because of bone metastasis of his disease.
Some other minor grade I or II side effects and toxicities were occasionally observed, but were not persistent or severe. There was no significant or rapid body weight loss in patients following DC vaccine injections. Taken together, these results indicate that the injection of rhCEApulsed DCs into late-stage colorectal cancer patients using our vaccination process is generally safe.

\section{Clinical and immune responses}

In the observation of clinical response of these patients, patients 5 and 12 showed stable disease after standard vaccination (Table 8). Therefore, these 2 patients received 2 and 1 boosting injection(s), respectively, until disease progression. The total duration of disease stable period was 105 and 98 days for patients 5 and 12 (Table 8). The other 10 patients had disease progression either during the treatment period or at the first evaluation time point after the treatment procedure. The overall rate of patients with clinical benefit was $16.7 \%$ for all 12 enrolled patients and $20 \%$ for the 10 patients completing the standard $4 \mathrm{DC}$ vaccination protocol.

For the investigation of immune responses after DC vaccination, PBMCs collected before and after DC vaccination were thawed at the same time for immunological analysis. Cells were cultured with $5-50 \mu \mathrm{g} / \mathrm{mL}$ of rhCEA for 5 days and then cellular proliferation was determined. Blood samples from 9 patients were analyzed for $\mathrm{T}$ cell responses against rhCEA; while blood samples after treatment were not available from 3 patients because of early disease progression and patients' reluctance to blood drawing, and were therefore not examined for $\mathrm{T}$ cell responses. As shown in Fig. 2, most $\mathrm{T}$ cell responses 
Table 6 Comparison of autoimmune profiles before, during, and after vaccination

\begin{tabular}{|c|c|c|c|c|c|c|c|c|c|}
\hline \multirow[t]{2}{*}{ Patient } & \multicolumn{3}{|c|}{ Antinuclear antibody } & \multicolumn{3}{|c|}{ Rheumatoid factor } & \multicolumn{3}{|c|}{ Thyroglobulin antibody } \\
\hline & $\begin{array}{l}\text { Day } 0 \\
\text { (before) }\end{array}$ & $\begin{array}{l}\text { Day } 36 \\
\text { (during) }\end{array}$ & $\begin{array}{l}\text { Day } 57 \\
\text { (after) }\end{array}$ & $\begin{array}{l}\text { Day 0 } \\
\text { (before) }\end{array}$ & $\begin{array}{l}\text { Day } 36 \\
\text { (during) }\end{array}$ & $\begin{array}{l}\text { Day } 57 \\
\text { (after) }\end{array}$ & $\begin{array}{l}\text { Day } 0 \\
\text { (before) }\end{array}$ & $\begin{array}{l}\text { Day } 36 \\
\text { (during) }\end{array}$ & $\begin{array}{l}\text { Day } 57 \\
\text { (after) }\end{array}$ \\
\hline 1 & $1: 40$ & $1: 40$ & $1: 40$ & $<20$ & $<20$ & $<20$ & $1: 40$ & $1: 40$ & $1: 40$ \\
\hline 2 & $1: 40$ & off $^{a}$ & off & $<20$ & off & off & 1.7 & off & off \\
\hline 3 & $1: 40$ & $1: 40$ & $1: 40$ & $<20$ & $<20$ & $<20$ & $1: 40$ & 6.21 & $1: 40$ \\
\hline 4 & $1: 40$ & $1: 80$ & off & $<20$ & $<20$ & off & $1: 40$ & $1: 40$ & off \\
\hline 5 & $(-)$ & $(-)$ & $(-)^{b}$ & $<20$ & 22.9 & 23.3 & $1: 80$ & $1: 80$ & $<1: 10$ \\
\hline 6 & $(-)$ & $(-)$ & $(-)$ & $<20$ & $<20$ & $<20$ & $1: 80$ & $<1: 10$ & $<1: 10$ \\
\hline 7 & $(-)$ & $(-)$ & $(-)$ & $<20$ & $<20$ & $<20$ & $1: 40$ & $1: 80$ & $1: 40$ \\
\hline 8 & $(-)$ & $(-)$ & off & $<20$ & $<20$ & off & $1: 80$ & $1: 40$ & off \\
\hline 9 & $(-)$ & $(-)$ & $(-)$ & 60.6 & 59.5 & 44.2 & $1: 160$ & $1: 80$ & $<1: 10$ \\
\hline 10 & $1: 640$ & $1:>1280$ & $1:>1280$ & $<20$ & 20.5 & 21.4 & $1: 40$ & $<1: 10$ & $1: 40$ \\
\hline 11 & $1: 40$ & $1: 40$ & $1: 40$ & $<20$ & $<20$ & $<20$ & 5.11 & 3.09 & 7.81 \\
\hline 12 & $1: 40$ & $1: 40$ & $1: 40$ & $<20$ & $<20$ & $<20$ & 14.2 & 0.71 & 1.14 \\
\hline
\end{tabular}

"off" indicates samples were not available for analysis due to withdraw or termination of enrolled patients from this study

a" off" indicates samples not available for analysis because of withdrawal or termination of enrolled patients from this study

$\mathrm{b}(-)$ : not detected

against rhCEA were not strong. In some of the patients, addition of rhCEA appears to induce cell death as reflexed by the significant reduction of BrdU incorporation. Patients 5 and 12 showed stable disease after standard vaccination and therefore received 2 and 1 boosting injection(s), respectively. The proliferation of $\mathrm{T}$ cells

Table 7 Frequency and grade of adverse events of the 12 patients

\begin{tabular}{lllll}
\hline Grade $^{\mathrm{a}}$ & I & II & III IV V \\
Adverse event & & & & \\
\hline Local pain & $3 / 12^{\mathrm{b}}$ & $2 / 12$ & & \\
Local swelling & & $1 / 12$ & & \\
Fever & $5 / 12$ & $2 / 12$ & & \\
Skin rash/itching/skin desquamation & $3 / 12$ & $2 / 12$ & & \\
Myalgia & $1 / 12$ & & & \\
Bilirubin & $4 / 12$ & $1 / 12$ & $2 / 12$ & $1 / 12$ \\
GPT & $9 / 12$ & $2 / 12$ & & \\
GOT & $9 / 12$ & $2 / 12$ & $1 / 12$ & \\
Hemorrhage (UGI $\left.{ }^{\mathrm{C}}\right)$ & & $1 / 12$ & & \\
Diarrhea/Mucocitis & $3 / 12$ & $1 / 12$ & $2 / 12$ & \\
Creatinine & $1 / 12$ & $1 / 12$ & & \\
Allergy & $1 / 12$ & $1 / 12$ & & \\
Anemia & $1 / 12$ & $1 / 12$ & & \\
Short of breath & $2 / 12$ & & & \\
Sweating & $1 / 12$ & & \\
Chillness & $1 / 12$ & & \\
Leg edema & $1 / 12$ & & \\
aAverse event was & & &
\end{tabular}

${ }^{a}$ Adverse event was determined using CTCAE version 4.0

b $3 / 12$ " indicates that 3 of 12 patients had at least one episode of a particular adverse event

${ }^{\mathrm{c}}$ UGI indicates upper gastrointestinal was determined with additional PBMCs collected on day 180 (patient 5) and day120 (patients 5 and 12). A statistically significant increase in the $\mathrm{T}$ cell proliferation against rhCEA (10 and $50 \mu \mathrm{g} / \mathrm{mL}$ ) was observed in patient 12 , but not in patient 5, with PBMCs collected on day 57 and day 120 , suggesting the presence of a persistent $\mathrm{T}$ cell response. A temporary significant increase in $\mathrm{T}$ cell proliferation against rhCEA $(10 \mu \mathrm{g} / \mathrm{mL})$ was observed in patient 9 with PBMCs collected on day 36.

\section{Discussion}

The results of this study indicated that the strategy of combining the DC vaccine with TT followed by low-dose

Table 8 Summary of DC vaccination and clinical responses

\begin{tabular}{lll}
\hline Patient & $\begin{array}{l}\text { DC injections } \\
\text { Regular (boosting) }\end{array}$ & Best response (duration) \\
\hline 1 & 4 & PD $^{\mathrm{a}}$ \\
2 & 2 & PD \\
3 & 4 & PD \\
4 & 4 & PD \\
5 & $4(2)$ & SD $(105$ days) \\
6 & 4 & PD \\
7 & 4 & PD \\
8 & 3 & PD \\
9 & 4 & PD \\
10 & 4 & PD \\
11 & 4 & PD \\
12 & $4(1)$ & SD (98 days) \\
\hline
\end{tabular}

aPD: progressive disease

${ }^{b} S D$ : stable disease 

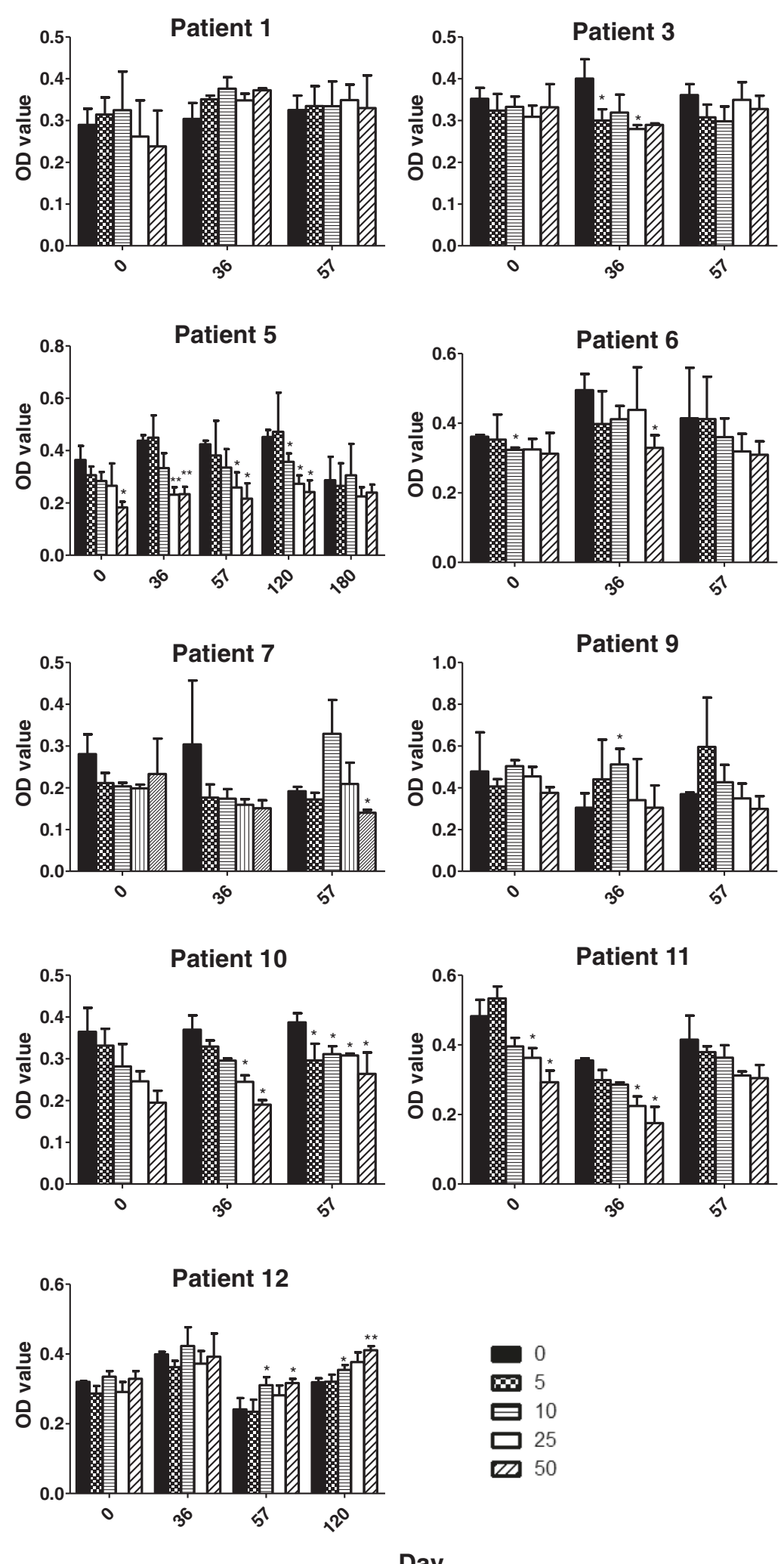

Fig. 2 (See legend on next page.) 
(See figure on previous page.)

Fig. 2 Proliferation against rhCEA by PBMCs collected before, during, and after DC vaccination from different patients. PBMCs collected before (day 0), during, and after DC vaccination (days 36, 57, 120, and 180) were cultured in 96-well culture plates for 5 days in the presence of 0 (PBS), 5, 10, 25, or $50 \mathrm{\mu g} / \mathrm{mL}$ rhCEA. Cellular proliferation was determined using a BrdU incorporation ELISA. T cell proliferation status was expressed as the $\mathrm{OD}$ value measured at $450 \mathrm{~nm}$ (reference wavelength $650 \mathrm{~nm}$ ). The OD value obtained from culture with different concentrations of rhCEA was compared to that of culture with PBS control. ${ }^{*} p<0.05,{ }^{* *} p<0.001$

IL-2 injection is generally safe for patients with late-stage CRC. No severe treatment-related toxicity was observed in any evaluable patients after DC vaccination. The vital signs of all patients were stable after vaccination. As described above, patients 2 and 8 showed early disease progression during the treatment period and only received 2 and 3 DC vaccinations, respectively. Patient 4 showed disease progression shortly after completion of the treatment. Some evaluation data were not available from these patients because of early withdrawal from the study. Patient 9 showed a higher level of rheumatoid factor before treatment, and the level slightly decreased during and after the 4 DC vaccine injections. Patient 12 showed a higher level of thyroglobulin antibody before treatment, and the level decreased during and after the 4 DC vaccine injections. Patient 1 had grade III diarrhea before treatment, and the symptom persisted during the trial period. Patient 2 had grade III diarrhea on day 22, but this was resolved soon after. Patient 6 had grade II creatinine elevation, likely because of the bone metastasis of his disease. Some other minor grade I or II side effects or toxicities were occasionally observed, but were not persistent or severe.

In this study, we found that vaccination of DCs pulsed with rhCEA is feasible and safe in the laboratory and clinical setting. Such vaccination may induce $T$ cell responses in certain cancer patients. However, these responses were moderate at best. In patient 12 with stable disease, the proliferation of $\mathrm{T}$ cells against rhCEA was detected at 57 and 120 days after initial injection. However, such increase in the $\mathrm{T}$ cell proliferation was not observed in patient 5 who also had stable disease after treatment. These results suggest that $\mathrm{T}$ cell proliferation against CEA may not be the most adequate method to determine the immune status in patients of this study, or the clinical benefit may result from immune responses against tumor-associated antigens other than CEA. Addition of rhCEA resulted in death of PBMCs from several patients in the $\mathrm{T}$ cell proliferation assay. We can not rule out the possibility that this is due to an antigen-induced apoptosis of T cells.

Attempts to stimulate or maintain a prolonged $\mathrm{T}$ cell response in vaccinated patients have been explored in many studies. These efforts include improvement of DC stimulation $[25,26]$, pre-conditioning of the vaccination site [27], and measures to maintain a long-lasting $\mathrm{T}$ cell response with cytokines or other biological agents [28]. We previously reported in animal models a strategy for pulsing DCs with CD40 ligand-transfected tumor cells and pre-conditioning with MIP-3 $\alpha$-transfected tumor cells $[29,30]$. Both approaches resulted in a better immune response against the tumor and effectively suppressed tumor growth and metastasis. This current study focused on the incorporation of the recall antigen TT in vaccine preparation and supplement of cytokines such as IL-2 after vaccination to increase the longevity of $\mathrm{T}$ cell responses. A recent study using TT to pre-condition the vaccination site of DCs pulsed with Cytomegalovirus phosphoprotein 65 RNA to treat glioblastoma patients also demonstrated an increase in the migration of DCs to draining lymph node and improved clinical outcomes [31]. Alternatively, strategies for removing or suppressing regulatory $\mathrm{T}$ cell activity in vivo were shown to enhance the $\mathrm{T}$ cell responses [28]. Another attractive strategy is to isolate $\mathrm{T}$ cells from patients after vaccination, expand and activate these $\mathrm{T}$ cells to a large quantity in vitro, and infuse the activated $\mathrm{T}$ cells back into the patients [32,33]. The expansion of $\mathrm{T}$ cells in vitro may potentially bypass the negative influence of regulatory $\mathrm{T}$ cells in the body. In addition, repeated infusions of a large number of tumor-associated antigen-specific $\mathrm{T}$ cells would be possible using this approach. Thus, a combination of different immunotherapy strategies, DC vaccination, and adoptive $\mathrm{T}$ cell therapy, may increase the efficacy of cancer treatment [18, 34]. We are currently investigating the potential of such combined immunotherapy.

\section{Conclusions}

The results of this clinical study were compatible to the safety data and clinical observation reported for other cancers involving DC-based immunotherapy $[15,16]$. Although the results of our clinical study are encouraging, most patients still showed disease progression during or after the DC vaccination. Additionally, these 12 patients were in the advanced disease stage and had failed all available treatments before entering this study. These results strengthen the view that DC-based immunotherapy should be performed in patients with early disease status or combined with other clinical interventions such as anti-immune checkpoint antibodies or adoptive $\mathrm{T}$ cell therapies to obtain better treatment outcomes. 


\section{Additional files}

Additional file 1: The complete inclusion and exclusion criteria of patient selection. (DOC $30 \mathrm{~kb}$ )

Additional file 2: The results of T cell proliferation assay. (XLS 93 kb)

\section{Acknowledgements}

The authors thank all subjects who participated in this study.

\section{Funding}

This study was supported by the intramural grant of the National Health Research Institutes to KJL.

\section{Availability of data and materials}

The datasets supporting the conclusions of this article are included within the article and its additional supporting files.

\section{Authors' contributions}

KJL and JWP designed and supervised research, and wrote manuscript. TSC, JYC, ALC and WYK recruited patients. HJC and YCW performed research. WLY and TRC helped patient data management. All authors read and approved the manuscript.

\section{Competing interests}

The authors declare that they have no competing interests.

\section{Consent for publication}

Not applicable.

\section{Ethics approval and consent to participate}

This clinical protocol was approved by the Research Ethics Committee of the National Taiwan University Hospital (protocol number 27MD02) and the Institutional Review Board of the Tri-Service General Hospital/National Defense Medical Center (protocol number 095-04-003), and further approved by the Department of Health (currently the Ministry of Health and Welfare), Taiwan. Signed informed consent was obtained from each patient before the recruitment.

\section{Author details}

${ }^{1}$ National Institute of Cancer Research, National Health Research Institutes, Tainan, Taiwan. ${ }^{2}$ Institute of Clinical Pharmacy and Pharmaceutical Sciences, National Cheng Kung University, Tainan, Taiwan. ${ }^{3}$ School of Medical Laboratory Science and Biotechnology, Taipei Medical University, Taipei, Taiwan. ${ }^{4}$ Division of Hematology/Oncology, Tri-Service General Hospital, Taipei, Taiwan. ${ }^{5}$ Department of Oncology, National Taiwan University Hospital, Taipei, Taiwan. ${ }^{6}$ Present Address: Department of Hematology/ Oncology, Taipei Medical University Shuang Ho Hospital, Taipei, Taiwan. ${ }^{7}$ Present Address: Division of Hematology/Oncology, Department of Internal Medicine, National Cheng Kung University Hospital, College of Medicine, National Cheng Kung University, Tainan, Taiwan. ${ }^{8}$ Present Address: Division of Hematology-Oncology, Department of Medicine, Taipei Tzu Chi Hospital, Taipei, Taiwan. ${ }^{9}$ Present Address: Comprehensive Cancer Center, Taipei Medical University, Taipei, Taiwan.

Received: 27 May 2016 Accepted: 5 August 2016

Published online: 24 August 2016

\section{References}

1. Siegel R, Desantis C, Jemal A. Colorectal cancer statistics, 2014. CA Cancer J Clin. 2014:64(2):104-17.

2. Cunningham D, Atkin W, Lenz HJ, Lynch HT, Minsky B, Nordlinger B, Starling N. Colorectal cancer. Lancet. 2010;375(9719):1030-47.

3. Postow MA, Callahan MK, Wolchok JD. Immune checkpoint blockade in cancer therapy. J Clin Oncol. 2015;33(17):1974-82.

4. Callahan MK. Immune checkpoint therapy in melanoma. Cancer J. 2016;22(2):73-80.

5. Marrone KA, Brahmer JR. Immune checkpoint therapy in non-small cell lung cancer. Cancer J. 2016;22(2):81-91.
6. Singh PP, Sharma PK, Krishnan G, Lockhart AC. Immune checkpoints and immunotherapy for colorectal cancer. Gastroenterol Rep (Oxf). 2015;3(4): 289-97. doi:10.1093/gastro/gov053.

7. Sharma P. Immune checkpoint therapy and the search for predictive biomarkers. Cancer J. 2016;22(2):68-72.

8. Le DT, Uram JN, Wang H, Bartlett BR, Kemberling H, Eyring AD, Skora AD, Luber BS, Azad NS, Laheru D, et al. PD-1 blockade in tumors with mismatchrepair deficiency. N Engl J Med. 2015;372(26):2509-20.

9. McGranahan N, Furness AJ, Rosenthal R, Ramskov S, Lyngaa R, Saini SK, Jamal-Hanjani M, Wilson GA, Birkbak NJ, Hiley CT, et al. Clonal neoantigens elicit T cell immunoreactivity and sensitivity to immune checkpoint blockade. Science. 2016;351(6280):1463-9.

10. Goldstein J, Tran B, Ensor J, Gibbs P, Wong HL, Wong SF, Vilar E, Tie J, Broaddus $\mathrm{R}$, Kopetz $\mathrm{S}$, et al. Multicenter retrospective analysis of metastatic colorectal cancer (CRC) with high-level microsatellite instability (MSI-H). Ann Oncol. 2014;25(5):1032-8.

11. Koopman M, Kortman GA, Mekenkamp L, Ligtenberg MJ, Hoogerbrugge $N$, Antonini NF, Punt CJ, van Krieken JH. Deficient mismatch repair system in patients with sporadic advanced colorectal cancer. Br J Cancer. 2009;100(2): 266-73.

12. Sharma P, Allison JP. Immune checkpoint targeting in cancer therapy: toward combination strategies with curative potential. Cell. 2015;161(2):205-14.

13. Carreno BM, Magrini V, Becker-Hapak M, Kaabinejadian S, Hundal J, Petti AA, Ly A, Lie WR, Hildebrand WH, Mardis ER, et al. Cancer immunotherapy. A dendritic cell vaccine increases the breadth and diversity of melanoma neoantigen-specific T cells. Science. 2015;348(6236):803-8.

14. Kleponis J, Skelton $\mathrm{R}$, Zheng $\mathrm{L}$. Fueling the engine and releasing the break: combinational therapy of cancer vaccines and immune checkpoint inhibitors. Cancer Biol Med. 2015;12(3):201-8.

15. Mody N, Dubey S, Sharma R, Agrawal U, Vyas SP. Dendritic cell-based vaccine research against cancer. Expert Rev Clin Immunol. 2015;11(2):213-32.

16. Bol KF, Schreibelt G, Gerritsen WR, de Vries IJ, Figdor CG. Dendritic cellbased immunotherapy: state of the art and beyond. Clin Cancer Res. 2016; 22(8):1897-906.

17. Cheever MA, Higano CS. PROVENGE (Sipuleucel-T) in prostate cancer: the first FDA-approved therapeutic cancer vaccine. Clin Cancer Res. 2011;17(11):3520-6.

18. Kajihara M, Takakura K, Kanai T, Ito Z, Saito K, Takami S, Shimodaira S, Okamoto M, Ohkusa T, Koido S. Dendritic cell-based cancer immunotherapy for colorectal cancer. World J Gastroenterol. 2016:22(17):4275-86.

19. Park JW, Chang HJ, Kim BC, Yeo HY, Kim DY. Clinical validity of tissue carcinoembryonic antigen expression as ancillary to serum carcinoembryonic antigen concentration in patients curatively resected for colorectal cancer. Colorectal Dis. 2013;15(9):e503-11.

20. Liu KJ, Wang CC, Chen LT, Cheng AL, Lin DT, Wu YC, Yu WL, Hung YM, Yang HY, Juang $\mathrm{SH}$, et al. Generation of carcinoembryonic antigen (CEA)-specific T-cell responses in HLA-A*0201 and HLA-A*2402 late-stage colorectal cancer patients after vaccination with dendritic cells loaded with CEA peptides. Clin Cancer Res. 2004;10(8):2645-51.

21. Hunyadi J, Andras C, Szabo I, Szanto J, Szluha K, Sipka S, Kovacs P, Kiss A, Szegedi G, Altorjay I, et al. Autologous dendritic cell based adoptive immunotherapy of patients with colorectal cancer-A phase I-II study. Pathol Oncol Res. 2014;20(2):357-65.

22. Constantino J, Gomes C, Falcao A, Cruz MT, Neves BM. Antitumor dendritic cell-based vaccines: lessons from 20 years of clinical trials and future perspectives. Transl Res. 2016;168:74-95.

23. Chang GC, Lan HC, Juang SH, Wu YC, Lee HC, Hung YM, Yang HY, WhangPeng J, Liu KJ. A pilot clinical trial of vaccination with dendritic cells pulsed with autologous tumor cells derived from malignant pleural effusion in patients with late-stage lung carcinoma. Cancer. 2005;103(4):763-71.

24. Timmerman JM, Czerwinski DK, Davis TA, Hsu FJ, Benike C, Hao ZM, Taidi B, Rajapaksa R, Caspar CB, Okada CY, et al. Idiotype-pulsed dendritic cell vaccination for B-cell lymphoma: clinical and immune responses in 35 patients. Blood. 2002;99(5):1517-26.

25. Zarnani AH, Torabi-Rahvar M, Bozorgmehr M, Zareie M, Mojtabavi N. Improved efficacy of a dendritic cell-based vaccine against a murine model of colon cancer: the helper protein effect. Cancer Res Treat. 2015;47(3):518-26.

26. Barth Jr RJ, Fisher DA, Wallace PK, Channon JY, Noelle RJ, Gui J, Ernstoff MS. A randomized trial of ex vivo CD40L activation of a dendritic cell vaccine in colorectal cancer patients: tumor-specific immune responses are associated with improved survival. Clin Cancer Res. 2010;16(22):5548-56. 
27. Prins RM, Craft N, Bruhn KW, Khan-Farooqi H, Koya RC, Stripecke R, Miller JF, Liau LM. The TLR-7 agonist, imiquimod, enhances dendritic cell survival and promotes tumor antigen-specific T cell priming: relation to central nervous system antitumor immunity. J Immunol. 2006;176(1):157-64.

28. Unger WW, Mayer CT, Engels S, Hesse C, Perdicchio M, Puttur F, Streng-Ouwehand I, Litjens M, Kalay H, Berod L, et al. Antigen targeting to dendritic cells combined with transient regulatory $T$ cell inhibition results in long-term tumor regression. Oncoimmunology. 2015;4(8):e970462.

29. Liu KJ, Lu LF, Cheng HT, Hung YM, Shiou SR, Whang-Peng J, Juang SH. Concurrent delivery of tumor antigens and activation signals to dendritic cells by irradiated CD40 ligand-transfected tumor cells resulted in efficient activation of specific CD8+ T cells. Cancer Gene Ther. 2004;11(2):135-47.

30. Shih NY, Yang HY, Cheng HT, Hung YM, Yao YC, Zhu YH, Wu YC, Liu KJ. Conditioning vaccination site with irradiated MIP-3alpha-transfected tumor cells enhances efficacy of dendritic cell-based cancer vaccine. J Immunother. 2009;32(4):363-9.

31. Mitchell DA, Batich KA, Gunn MD, Huang MN, Sanchez-Perez L, Nair SK, Congdon KL, Reap EA, Archer GE, Desjardins A, et al. Tetanus toxoid and CCL3 improve dendritic cell vaccines in mice and glioblastoma patients. Nature. 2015;519(7543):366-9.

32. Kandalaft LE, Powell Jr DJ, Chiang CL, Tanyi J, Kim S, Bosch M, Montone K, Mick R, Levine BL, Torigian DA, et al. Autologous lysate-pulsed dendritic cell vaccination followed by adoptive transfer of vaccine-primed ex vivo co-stimulated T cells in recurrent ovarian cancer. Oncoimmunology. 2013;2(1):e22664.

33. Morisaki T, Matsumoto K, Onishi H, Kuroki H, Baba E, Tasaki A, Kubo M, Nakamura M, Inaba S, Yamaguchi K, et al. Dendritic cell-based combined immunotherapy with autologous tumor-pulsed dendritic cell vaccine and activated T cells for cancer patients: rationale, current progress, and perspectives. Hum Cell. 2003;16(4):175-82.

34. Datta J, Berk E, Cintolo JA, Xu S, Roses RE, Czerniecki BJ. Rationale for a multimodality strategy to enhance the efficacy of dendritic cell-based cancer immunotherapy. Front Immunol. 2015;6:271.

\section{Submit your next manuscript to BioMed Central and we will help you at every step:}

- We accept pre-submission inquiries

- Our selector tool helps you to find the most relevant journal

- We provide round the clock customer support

- Convenient online submission

- Thorough peer review

- Inclusion in PubMed and all major indexing services

- Maximum visibility for your research

Submit your manuscript at www.biomedcentral.com/submit

C Biomed Central 